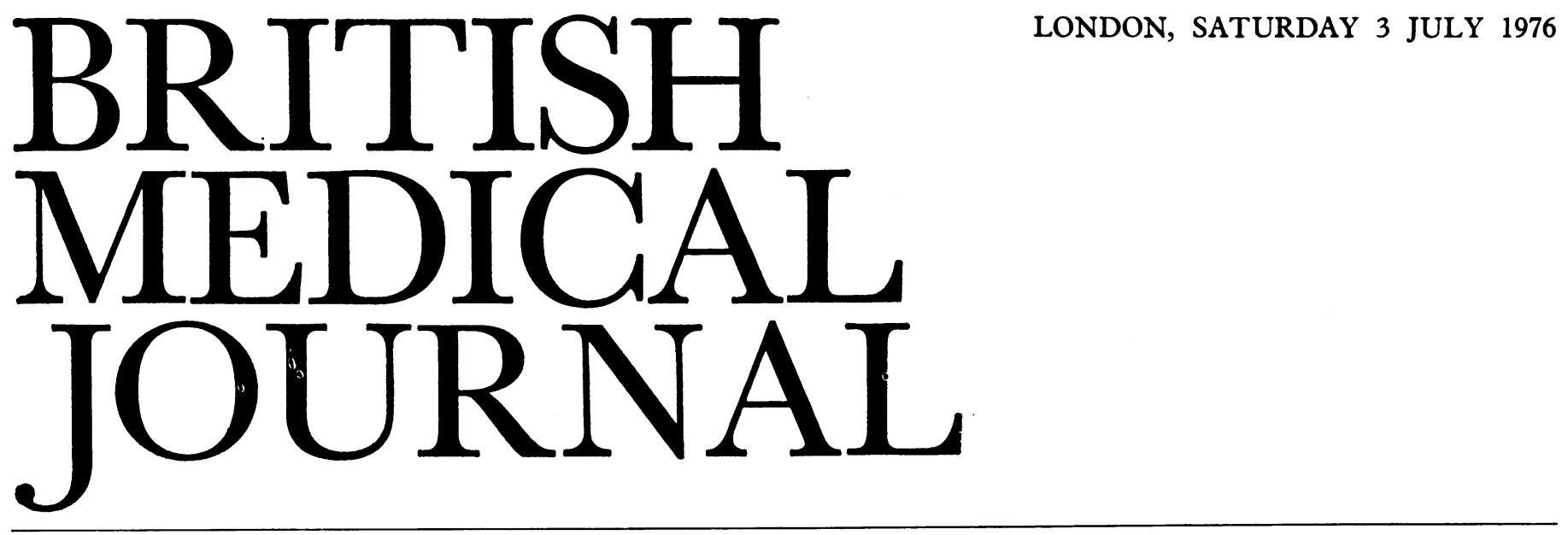

\title{
Shellfish and public health
}

\author{
"-she wheeled her wheelbarrow \\ Through streets broad and narrow, \\ Crying cockles and mussels, \\ Alive, alive $O$ '"
}

And therein lie keys to some of the potential health hazards associated with shellfish and other seafoods, reviewed previously in the $B M \mathcal{F}^{1}$ and elsewhere, ${ }^{2}$ and highlighted again by a recent outbreak of viral hepatitis associated with oysters in America. ${ }^{3}$ Shellfish include molluscs such as oysters, mussels, cockles, and clams as well as crustacea such as crabs, lobsters, shrimps, and prawns. The latter are usually cooked and the risks of bacterial or viral infection are therefore reduced -though, as with other foods, contamination with pathogens such as Staphylococcus aureus and salmonellas may subsequently occur: the poorer the hygiene, the greater the risks. Since oysters in particular, and mussels sometimes, are normally marketed alive and eaten raw, this protection from cooking or preservation does not apply, and they are thus potentially more hazardous. The degree of risk, however, varies from one country to another, depending on geography, climate, economic conditions, customs, and living standards. Bivalve molluscs, moreover, feed by filtering and concentrating microscopic particles, including any bacteria and viruses present, from the large volumes of water passed through their gills, and they thrive in sewage-polluted waters. With adequate purification and control, health hazards from such shellfish can be reduced, as in Britain, to acceptable levels. But there can never be an absolute no-risk guarantee, and the traveller abroad must beware.

Apart from viral hepatitis most illnesses associated with shellfish fall into one or other of three categories: neuroparalytic; allergic reactions; and gastrointestinal disturbances. Of these, paralytic shellfish poisoning is caused indirectly by photosynthesising marine dinoflagellates-the "grass of the sea"-responsible for the coloured surface blooms well known to sailors and the red tides in tropical and warm waters. These organisms produce potent heat- and acid-stable toxins, affecting only vertebrate animals, which shellfish accumulate physiologically without harm to themselves. Although not uncommon in warm climates, illness from these toxins is fortunately rare in Britain, only 10 incidents having been reported during the last 150 years. ${ }^{4}$ The most recent outbreak occurred in the summer of 1968 on the North-east coast, ${ }^{5}$ and since then shellfish have been monitored regularly for the presence of the toxins. Although the symptoms are typically neurotoxic, ${ }^{6}$ clinical and epidemiological awareness is essential for early detection of the condition.

Allergic reactions to shellfish, especially urticaria and other rashes, are well known by repute but there are relatively few published accounts. With oysters and mussels a rapid gastrointestinal response-severe abdominal cramps and vomiting almost within the hour-may even be more common than urticaria. Much of this is only hearsay, and there is need for real evidence, including clinical and laboratory studies, to evaluate the nature and size of the problem.

Much more common are infections due to faecal pollution, which thus reflect disease already endemic in the community. Typhoid from shellfish still occurs in some countries across the channel, and other potential hazards-as well as the importance of effective control of harvesting and sale-are well illustrated by the role of shellfish in the outbreaks of cholera in Italy and Portugal in 1974. In Britain the use of Escherichia coli as the most sensitive bacterial indicator of faecal pollution-and thus the safety of raw shellfish for human consumption-has largely prevented transmission of most of the known communicable diseases. Elsewhere, outbreaks of viral hepatitis, linked epidemiologically with shellfish, may have originated from supplies which had they been tested at the time might well have been rejected on bacteriological grounds. The American report, ${ }^{3}$ however, suggests that oysters may possibly retain hepatitis virus long after $E$ coli has gone. This interesting speculation is based on an outbreak traced to oysters from one area where harvesting was prohibited after heavy flooding and sewage contamination for some two months after the growing waters were considered pollution-free as judged by coliform tests. But the oysters themselves were not examined. The apparent failure in safety suggests, perhaps, that the risk of potential viral infections should not be based on extrapolation from bacteriological tests unless, as with water supplies, monitoring is carried out regularly and frequently.

Some incidents associated with oysters where no causal agent was identified 78 have closely resembled viral gastroenteritis, such as the summer diarrhoea-winter vomiting syndrome. ${ }^{9}$ Nevertheless, we also have to consider the way in which supplies are handled before consumption, especially as raw shellfish from sewage-polluted waters sometimes yield high bacterial counts at $37^{\circ} \mathrm{C}$ even when $E$ coli is absent. In addition they usually contain organisms naturally present in the marine environment, and these may also be relevant. 
The marine bacterium Vibrio parahaemolyticus, a known cause of gastroenteritis from seafoods, especially abroad, ${ }^{1011}$ also occurs in British coastal waters ${ }^{12}$-though only one incident traced to home-produced crabmeat has been reported. ${ }^{13}$ The vibrio is often present in imported crustacea, especially shrimps and prawns from the Far East, and these have been reponsible for some recent incidents. ${ }^{14}$ Though this organism may multiply rapidly, even at low temperatures, it is fully sensitive to heat: as with most microbial pathogens control thus lies in sound hygienic practice during and after processing. The consumption of any food raw inevitably carries some risks to health, and shellfish are no exception. Adequate heat treatment would, however, overcome most of them. Perhaps further education in cooking and eating these interesting foods is needed-who's for oyster or mussel pie?

\footnotetext{
${ }^{1}$ British Medical fournal, 1975, 3, 393.

${ }^{2}$ Barrow, G I, Postgraduate Medical fournal, 1974, 50, 612.

${ }^{3}$ Mackowiak, P A, Caraway, C T, and Portnoy, B L, American fournal of Epidemiology, 1976, 103, 181.

4 Ayres, P A, Environmental Health, 1975, 83, 261.

5 Ingham, H R, Mason, J, and Wood, P C, Nature, 1968, 220, 25.

6 McCollum, J P K, et al, Lancet, 1968, 2, 767.

7 Gunn, A D G, and Rowlands, D F, Medical Offlcer, 1969, 122, 75.

${ }^{8}$ Preston, F S, Aerospace Medicine, 1968, 39, 519.

${ }^{9}$ Clarke, S K R, et al, British Medical fournal, 1972, 3, 86.

10 Sakazaki, R, in The Microbiological Safety of Food, ed B C Hobbs and J H B Christian, p 19. London, Academic Press, 1973.

11 Peffers, A S R, et al, Lancet, 1973, 1, 143.

12 Barrow, G I, and Miller, D C, Lancet, 1972, 1, 485.

${ }^{13}$ Hooper, W L, Barrow, G I, and McNab, D J N, Lancet, 1974, 1, 1100

${ }^{14}$ Barrow, G I, and Miller, D C, in press.
}

\section{Crohn's colitis and ileorectal anastomosis}

When medical treatment fails to control the symptoms of Crohn's colitis excising the diseased bowel offers the only prospect of restoring the patient to health. The operation most commonly done is a proctocolectomy; this leaves the patient with a permanent ileostomy. Less commonly, when the distal bowel disease is minimal, the rectum may be spared and bowel continuity restored by an ileorectal anastomosis. Preservation of the normal sphincter mechanism is obviously an attractive alternative for the patient, but what, if any, are the hidden disadvantages?

In recent years several large series have described the late results of the surgical treatment of patients suffering from Crohn's colitis. ${ }^{1-5}$ Altogether 225 patients underwent proctocolectomy with permanent ileostomy and 72 patients had a total colectomy and ileorectal anastomosis. Clearly the two groups were not strictly comparable: the bias was almost certainly in favour of the patient with ileorectal anastomosis group, as this operation is contraindicated in patients with severe rectal disease and perirectal suppuration. The overall recurrence rate for patients undergoing proctocolectomy was $25 \%$, but for patients undergoing ileorectal anastomosis it was nearly three times as high $-73 \%$. The operative mortality rate was a little higher for proctocolectomy, but again this may have reflected differences in the severity of the disease in the two groups.

The most recently reported series ${ }^{5}$ has analysed the fate of 21 patients undergoing ileorectal anastomosis in great detail. Twenty patients were followed for a mean of 8.3 years (one patient died three years after the first operation after further surgery for recurrent ileal disease). Only five of the 20 patients remained free of recurrence. Of the remainder, recurrence developed at the anastomotic site in 13 of the 15 patients. Nine patients required a further operation, and in five this meant excision of the rectum. So at the time of follow-up, though 14 of the 20 original patients still had their ileorectal anastomosis intact, nine had obvious recurrent disease, which at that time had been controlled medically.

These results do not enable the surgeon to be dogmatic $\frac{0}{c}$ about the correct advice to an individual patient needing colectomy for Crohn's colitis. In each case the two-fold or $\stackrel{0}{\rightarrow}$ three-fold increased risk of recurrent disease which seems to be associated with ileorectal anastomosis has to be balanced $\frac{\bar{\sigma}}{\bar{c}}$ against the disadvantage of permanent ileostomy. Perhaps the most puzzling feature is why there should be an increased risk of recurrence after ileorectal anastomosis, as the rectum is $\omega$ virtually normal in many of these patients. Does the minimal $\vec{\circ}$ residual disease in the rectal stump relight? Or does the $\overrightarrow{\vec{\omega}}$ preservation of the sphincter in some way affect the suscepti- ${ }^{\circ}$ bility of the small bowel to develop further recurrence?

1 Steinberg, D M, et al, Gut, 1974, 15, 845.

2 Ritchie, J K, and Lockhart-Mummery, H E, Gut, 1973, 14, 263.

3 Nugent, F W, et al, Gastroenterology, 1973, 65, 398.

4 De Dombal, F T, Burton, I, and Goligher, J C, Gut, 1971, 12, 519

5 Weterman, I T, and Pena, A S, Scandinavian fournal of Gastroenterology, $1976,11,185$

\section{Vitamin $A$ and cancer prophylaxis}

There has been growing over many years a rich store of $\mathbb{\mathscr { Q }}$ publications on the possible relevance of vitamin $A$ and its $\overrightarrow{\vec{O}}$ analogues to the risk of development of cancer, and squamous 3 carcinoma in particular. In the light of this mass of reports the sponsorship $^{1}$ by the USA National Cancer Institute of clinical trials of the value of a vitamin $\mathrm{A}$ analogue as a cancer preventive should occasion no real surprise.

Normally the external parts of the body and its entrances and exits (mouth, pharynx, anus, and vagina) are lined by squamous epithelium, whereas the gut, lower respiratory $\frac{\rho}{3}$ passages, gall bladder, and endocervix are lined by glandular 0 epithelium. Sometimes normally glandular epithelium be- $\vec{J}$ comes squamous and whenever such "squamous metaplasia" O occurs there are grounds for suspecting increased risk of $\frac{D}{2}$ cancer development. In the fetus, and to a lesser extent in mature animals, vitamin A deficiency predisposes to squamous metaplasia; adequate levels of vitamin A protect against its $\omega$ development; and (especially in immature animals) excessive levels of the vitamin encourage replacement of normally $\stackrel{\circ}{工}$ squamous epithelium by the glandular type-so-called mucous $\stackrel{\mathscr{\Phi}}{\rightarrow}$ metaplasia.

Convincing evidence for these statements comes both from in-vitro ${ }^{23}$ and in-vivo studies. ${ }^{4}$ More direct evidence $\stackrel{\mathbb{Q}}{\stackrel{\Phi}{Q}}$ of the value of vitamin $A$ in protection against cancer has $\stackrel{\mathbb{Q}}{2}$ come from experiments in which tissues in organ culture or in intact animals were exposed to carcinogenic polycyclic 8 aromatic hydrocarbons (PAH) in such a way that they developed squamous cancers. ${ }^{5-7}$ Cone and Nettesheim showed ${ }^{8} \frac{\overline{\overline{0}}}{\overline{7}}$ that vitamin A protected rats against the early development $\stackrel{F}{F}$ of squamous neoplasms in response to a carcinogen, 3methylcholanthrene, given by endotracheal instillation. Their findings were particularly important because these workers measured the amount of vitamin A stored in the liver to 